\title{
The Study on the General Situation of Chinese Cultural Non-Profit Organization \\ --Based on the Empirical Research from 2007 to 2012
}

\author{
Xiaofei Gai ${ }^{1, a}$, Xuefang Xie ${ }^{2, b}$ \\ ${ }^{1}$ Room 601,Building 7,NO.28,Tieling Road,Yangpu District,Shanghai City, P.R. China,200092 \\ ${ }^{2}$ No.1239,Siping Road School of Humanities, Tongji University,Shanghai City, P.R. China,200092, \\ ${ }^{1}$ istfhwx@163.com , ${ }^{2}$ xxf850@163.com
}

Keywords: cultural non-profit organization;development structure;regional distribution;the empirical Abstract. As the intermediary to the development of cultural industries, the cultural non-profit organization plays an important role. The text makes an analysis about the cultural non-profit organization of China from the perspective of the development trend and structure of Chinese cultural non-profit organization, the regional distribution of the cultural non-profit organization, the development situation of cultural non-profit organization compared to the non-profit organizations and cultural organizations in the nationwide, just based on the research and data statistics from 2007 to 2012.

\section{Introduction}

As the intermediary to the development of cultural industries, the cultural non-profit organization (cultural NPO) plays an increasingly important role in the following areas with the promotion of cultural industries status: mobilizing social and cultural resources,participating in social coordination and control,supervising the formulation and implementation of public legislation on behalf of the media and public opinion,maintaining social harmony. ${ }^{[1]}$ The cultural non-profit organization generally include three parts: social group, people-run non-enterprise unit and foundation.

\section{The development trend and structure analysis of Chinese cultural non-profit organization}

As shown in Figure 1, the current development situation of Chinese cultural non-profit organization are: the total numbers of the cultural NPO, social group and people-run non-profit unit are increasing year by year; the quantity of the foundation is in local reduction (the year from 2007 to 2008 and 2011 to 2012) but overall increase.

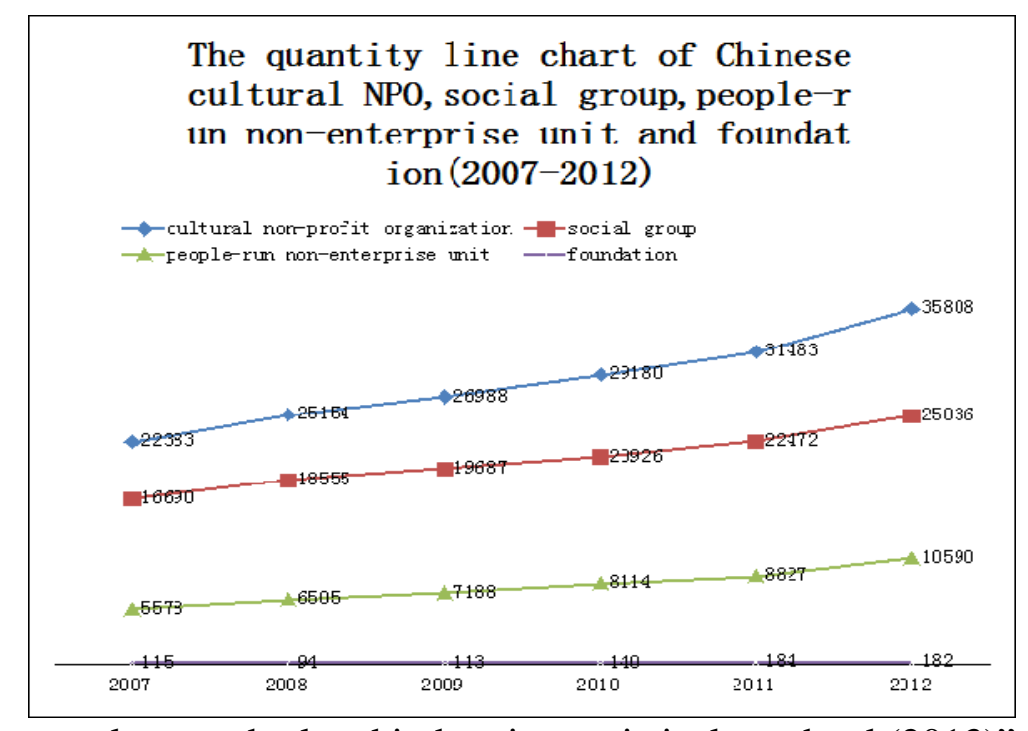

Data resource:"Chinese culture and related industries statistical yearbook(2013)”

Figure 1: The quantity line chart of Chinese cultural NPO,social group,people-run non-enterprise unit and foundation(2007-2012) [UNIT:AMOUNT] 
The total number of cultural NPO in China in the year of 2007 and 2011 is more substantial than the previous year, the growth rate are $12.38 \%$ and $13.74 \%$ respectively as shown in Table 1 . The growth trends of social group and people-run non-enterprise unit maintain a general agreement with the growth trend of cultural NPO. From 2009 to 2010 and 2010 to 2011, the growth rates of the number of cultural foundation are $23.89 \%$ and $31.43 \%$ respectively. And the growth trend of cultural foundation is different from the other three:in the year of 2007-2008 and 2011-2012, the total number of it is reduced, the reduction ratio are $18.26 \%$ and $1.09 \%$ respectively.

Table 1: Annual growth rate of Chinese cultural non-profit organization [UNIT:PERCENTAGE]

\begin{tabular}{|l|l|l|l|l|}
\hline Age & Cultural NPO & $\begin{array}{l}\text { Social } \\
\text { Group }\end{array}$ & Foundation & $\begin{array}{l}\text { People-run } \\
\text { non-enterprise } \\
\text { unit }\end{array}$ \\
\hline $2007-2008$ & 12.38 & 11.17 & -18.26 & 16.62 \\
\hline $2008-2009$ & 7.29 & 6.1 & 16.81 & 10.50 \\
\hline $2009-2010$ & 8.12 & 6.29 & 23.89 & 12.89 \\
\hline $2010-2011$ & 7.78 & 7.38 & 31.43 & 8.79 \\
\hline $2011-2012$ & 13.74 & 11.41 & -1.09 & 19.97 \\
\hline
\end{tabular}

In the organizations of Chinese cultural NPO, the social group occupy the vast majority as shown in Table 2, the number of people-run non-enterprise unit is second largest, the proportion of the foundation is the smallest. As the development of the Chinese cultural NPO, the proportion of cultural social group is gradually reduced, downs from the $74.57 \%$ in 2007 to $69.92 \%$ in 2012 . The proportion of foundation is slightly floating during 2007-2012, but there is no change in the overall trend. During 2007-2012, the proportion of the people-run non- enterprise unit has been improved, roses from the $24.92 \%$ in 2007 to $29.57 \%$ in 2012.

Table 2: The proportion of Chinese cultural non-profit organization during 2007-2012 [UNIT:PERCENTAGE]

\begin{tabular}{|l|l|l|l|}
\hline Age & Social Group & Foundation & $\begin{array}{l}\text { People-run } \\
\text { non-enterprise } \\
\text { unit }\end{array}$ \\
\hline 2007 & 74.57 & 0.51 & 24.92 \\
\hline 2008 & 73.77 & 0.37 & 25.86 \\
\hline 2009 & 72.95 & 0.42 & 26.63 \\
\hline 2010 & 71.71 & 0.48 & 27.81 \\
\hline 2011 & 71.38 & 0.58 & 28.04 \\
\hline 2012 & 69.92 & 0.51 & 29.57 \\
\hline
\end{tabular}

According to the series of data, Chinese cultural NPO is now in a developing stage. But what can not be ignored is that the absolute quantity of foundation is very small. The foundation plays an vital role in many ways, such as providing social and public services, participating in social governance and providing adequate funding for cultural projects. The inferiority in number of foundation will seriously hinder it to play its function. In order to solve this kind of problem, the relevant government departments should improve the policy system, including tax policy, fiscal policy and so on. In the meantime, the communities should be concerned about the public welfare to create a nice atmosphere for the development of Chinese cultural NPO.

\section{The regional distribution structure of Chinese cultural non-profit organization}

At present, the features of regional distribution structure of Chinese cultural NPO are: the regional distribution is not uniform; the cultural non-profit organizations are mainly in the eastern coastal areas and minority inland developed areas; in the remote areas, the cultural resource is in shortage. 
In the region distribution, the top four of the quantity of cultural NPO in China are Shandong, Jiangsu, Guangdong and Zhejiang province. The numbers of cultural NPO in these four provinces are all more than 2000. The sum of these four areas occupies nearly 1/3(about 32.1\%) of the national cultural NPO. It is obviously that this situation keeps consistent with current situation of China economic development. Thus it can be seen that the development of culture is closely linked with the development of economy and also the economic progress has an important role in promoting the development of culture. In the same time, the top four provinces have a common ground: the cultural industries is developed by comparison. Taking Shandong Province ranking first as an example, its system of laws and regulations is perfect and its cultural policies are with the times. In the last five years, so many cultural policies and cultural industries policies are published. All of these policies are designed in many areas. Among them, taking "build a financing platform to support the development of the cultural industries(in Chinese)"(2009) as a representative,the number of this kind of cultural industries planning documents is about 15;taking "the construction of national and provincial parks in Shandong Province(in Chinese)"(2012) as a representative, the number of this kind of related document of the cultural industry base parks is 7; and the number of the kind of cultural industries activities and dynamic documents is 107 . These series of regulations are all related to the content to support the development of non-profit organization. They provide the guarantee for the development of the cultural industries in Shandong province. And in the same time, they promote the prosperity of the folk culture industries projects and create a good social, cultural and economic environment for the development of non - profit organization of folk culture.

Furthermore, in the number of cultural non-profit organizations in Beijing, Shanghai, Tianjin and Chongqing these four municipalities directly under the central government, Chongqing City is in the first place. The number is 612 . Through the data comparison, the main reason for this situation is that the social groups in Chongqing are more than the other three areas. The reason why the Chongqing area social groups are more is that Chongqing city is extremely important in the area of economic circle and cultural circle in Southwest China. On the other hand, weak political atmosphere in a certain extent in Chongqing City also provides a good and relaxed social environment for the folk organizations to carry out various types of folk activities. The number of social group in a certain extent is a reflection of the active degree of folk culture in a region. ${ }^{[2]}$ And this is a benign cycle:the existence of various social group provides the platform, capital, policy, personnel and other aspects for the development of the rich and colorful folk activities;and the vigorous development of civil society activities will also give birth to a more diversified social groups.

In addition, it can be seen through Table 3 that the number of foundation and people-run non-enterprise unit in Chongqing city is relatively small compared with the number of Beijing city and Shanghai city. This is because the establishment and maintenance of foundation and people-run non-enterprise unit need sufficient economic basis. Compared with Beijing and Shanghai, Chongqing City's economy and culture have no advantage.This has resulted in the number of foundation and people-run non-enterprise unit in Chongqing City can not be comparable to social group.

By the end of 2012, there is only one fund in Guangdong province. Beijing City is up to 38, followed by the central level, Hunan Province, Shanghai City, Zhejiang province and Shaanxi Province. The main reasons for this phenomenon are various. Firstly, the sponsors or the person in charge of the cultural foundation will generally choose the region as its base, which has a long history of culture, a deep cultural background or a relatively mature culture economic, and thus the Beijing City, Hunan Province, Shanghai City, Zhejiang province and Shaanxi province with deep culture atmosphere will become the first choice rather than the Guangdong area. Secondly, the degree of marketization in Guangdong area is high, and as a result, it has small demand for capital from the official or non-profit, the active private capital reduces the requirements of the fund's funds ${ }^{[3]}$.This has become one of the reasons that the foundation registration number of the Guangdong area is less.

Also as shown in Table 3, the number of cultural non-profit organization is less in most of China's frontier regions, including Tibet Autonomous Region,the Xinjiang Uygur Autonomous Region, Hainan Province and the Inner Mongolia Autonomous Region and in the northwest and southwest areas in China. This development status quo has a close relationship with the imbalance of China's 
economic development in the East, Central and the West. The backwardness of economic development has affected the construction of basic cultural facilities in these areas and Hindered the development of cultural industries. So as to influence the development of the culture NPO further more.

In the nationwide, the number of foundation in parts of the regional is zero, such as Hebei, the Guangxi Zhuang Autonomous Region, Guizhou, Xinjiang Uygur Autonomous Region and Qinghai region.

Specific circumstances are shown in table 3:

Table 3: Regional distribution of Chinese cultural non-profit organization[UNIT:AMOUNT]

\begin{tabular}{|c|c|c|c|c|}
\hline District & Cultural NPO & Social Group & Foundation & $\begin{array}{c}\text { People-run non-enterprise } \\
\text { unit }\end{array}$ \\
\hline
\end{tabular}

\begin{tabular}{|c|c|c|c|c|}
\hline Central level & 196 & 176 & 17 & 3 \\
\hline Chongqing & 612 & 513 & 2 & 97 \\
\hline Shanghai & 562 & 280 & 13 & 269 \\
\hline Beijing & 480 & 260 & 38 & 182 \\
\hline Tianjin & 256 & 161 & 8 & 87 \\
\hline
\end{tabular}

\begin{tabular}{|c|c|c|c|c|}
\hline Shandong & 3289 & 1773 & 5 & 1511 \\
\hline Jiangsu & 3047 & 2079 & 6 & 962 \\
\hline Guangdong & 2823 & 1874 & 1 & 948 \\
\hline Zhejiang & 2323 & 1494 & 11 & 818 \\
\hline
\end{tabular}

\begin{tabular}{|c|c|c|c|c|}
\hline Sichuan & 1943 & 1555 & 4 & 384 \\
\hline Henan & 1887 & 1251 & 6 & 630 \\
\hline Hubei & 1754 & 973 & 5 & 776 \\
\hline Fujian & 1638 & 1352 & 3 & 283 \\
\hline Shanxi(Shan) & 1574 & 1091 & 10 & 473 \\
\hline Hunan & 1315 & 905 & 14 & 396 \\
\hline Anhui & 1306 & 1047 & 5 & 254 \\
\hline Yunnan & 1151 & 1034 & 3 & 114 \\
\hline Shanxi(Jin) & 1030 & 762 & 6 & 262 \\
\hline Liaoning & 1027 & 722 & 6 & 299 \\
\hline
\end{tabular}

\begin{tabular}{|c|c|c|c|c|}
\hline Jiangxi & 972 & 705 & 2 & 265 \\
\hline Hebei & 966 & 741 & 0 & 225 \\
\hline Heilongjiang & 901 & 734 & 2 & 165 \\
\hline Gansu & 854 & 580 & 2 & 272 \\
\hline Jilin & 645 & 549 & 1 & 95 \\
\hline $\begin{array}{c}\text { The Inner } \\
\text { Mongolia } \\
\text { Autonomous } \\
\text { Region }\end{array}$ & 621 & 475 & 3 & 143 \\
\hline $\begin{array}{c}\text { The Guangxi } \\
\text { Zhuang } \\
\text { Autonomous } \\
\text { Region }\end{array}$ & 590 & 456 & 0 & 134 \\
\hline Guizhou & 562 & 487 & & \\
\hline The Xinjiang & 525 & 338 & 0 & 75 \\
\hline
\end{tabular}




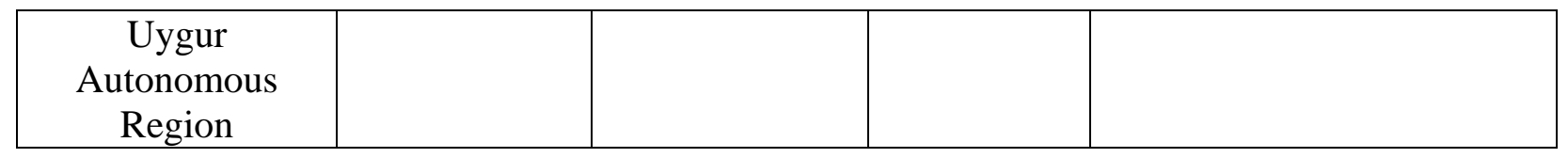

\begin{tabular}{|c|c|c|c|c|}
\hline Hainan & 406 & 304 & 3 & 99 \\
\hline Qinghai & 252 & 158 & 0 & 94 \\
\hline $\begin{array}{c}\text { The Ningxia Hui } \\
\text { Autonomous } \\
\text { Region }\end{array}$ & 229 & 139 & 3 & 87 \\
\hline $\begin{array}{c}\text { Tibet } \\
\text { Autonomous } \\
\text { Region }\end{array}$ & 72 & 68 & 3 & 1 \\
\hline
\end{tabular}

Note: Hong Kong, Macao and Taiwan are not included because of missing data.

Data resource:"Chinese culture and related industries statistical yearbook(2013)”

It can be seen from the analysis above that although the number of Chinese cultural non-profit organization is in the continuous increase, there is a serious imbalance in regional development. The imbalance in the economic foundation has resulted in the embarrassing situation of the development of the cultural non-profit organization. In order to change this awkward situation, it is not just the need to have policy tilt at the cultural policy level, to ensure the development of the central and western economy is also necessary. The relevant departments should provide a certain policy tilt in the formulation of economic policy to promote the culture development by economic and to create opportunities for the development of the cultural industries.

\section{The status quo of cultural non - profit organization in non-profit organization in China}

The number of non-profit organizations in China is increasing year by year. The cultural NPO also keep consistent with this trend. Among them, the cultural foundation's change trend is different from National Foundation's change trend. The number of national foundation is to maintain the trend of increasing year by year, but the cultural foundation's number is in local reduction and overall increase during 2007-2012.

Specific circumstances are shown in Table 4:

Table 4:The general situation of non-profit organization and cultural non-profit organization in China [UNIT:AMOUNT]

\begin{tabular}{|c|c|c|c|c|c|c|c|c|}
\hline \multirow[t]{2}{*}{ Age } & \multicolumn{2}{|c|}{ Organization } & \multicolumn{2}{|c|}{ Social Group } & \multicolumn{2}{|c|}{ Foundation } & \multicolumn{2}{|c|}{ People-run non-enterprise unit } \\
\hline & NPO & $\begin{array}{c}\text { Cultural } \\
\text { NPO }\end{array}$ & $\begin{array}{l}\text { Social } \\
\text { Group }\end{array}$ & $\begin{array}{c}\text { Cultural } \\
\text { Social } \\
\text { Group }\end{array}$ & $\begin{array}{c}\text { Foun } \\
\text { dation }\end{array}$ & $\begin{array}{c}\text { Cultura } \\
1 \\
\text { Founda } \\
\text { tion }\end{array}$ & $\begin{array}{l}\text { People-run } \\
\text { non-enterpris } \\
\text { e unit }\end{array}$ & $\begin{array}{c}\text { Cultural } \\
\text { People-run } \\
\text { non-enterprise } \\
\text { unit }\end{array}$ \\
\hline 2007 & 386916 & 22383 & 211661 & 16690 & 1340 & 115 & 173915 & 5578 \\
\hline 2008 & 413660 & 25154 & 229681 & 18555 & 1597 & 94 & 182382 & 6505 \\
\hline 2009 & 431069 & 26988 & 238747 & 19687 & 1843 & 113 & 190479 & 7188 \\
\hline 2010 & 445631 & 29180 & 245256 & 20926 & 2200 & 140 & 198175 & 8114 \\
\hline 2011 & 461971 & 31483 & 254969 & 22472 & 2614 & 184 & 204388 & 8827 \\
\hline 2012 & 499268 & 35808 & 271131 & 25036 & 3029 & 182 & 225108 & 10590 \\
\hline
\end{tabular}

Data resource:”Chinese culture and related industries statistical yearbook(2013)”

As shown in Table 5, the proportion of cultural NPO in China NPO is increasing year by year. Cultural social groups and cultural people-run non-enterprise units maintain the same trend. The proportion of cultural foundation in the national foundation is locally increase(from 2008 to 2011) but overall decrease (downs from $8.58 \%$ in 2007 to $6.01 \%$ in 2012). 
Table 5:The general situation of Chinese cultural non-profit organization accounting for the proportion of the non-profit organization in China during 2007-2012 [UNIT:PERCENTAGE]

\begin{tabular}{|c|c|c|c|c|}
\hline Age & Cultural NPO & $\begin{array}{c}\text { Cultural social } \\
\text { group }\end{array}$ & $\begin{array}{c}\text { Cultural } \\
\text { foundation }\end{array}$ & $\begin{array}{c}\text { Cultural people-run } \\
\text { non-enterprise unit }\end{array}$ \\
\hline 2007 & 5.78 & 7.89 & 8.58 & 3.21 \\
\hline 2008 & 6.08 & 8.08 & 5.89 & 3.57 \\
\hline 2009 & 6.26 & 8.25 & 6.13 & 3.77 \\
\hline 2010 & 6.55 & 8.53 & 6.36 & 4.09 \\
\hline 2011 & 6.81 & 8.81 & 7.04 & 4.32 \\
\hline 2012 & 7.17 & 9.23 & 6.01 & 4.70 \\
\hline
\end{tabular}

The reasons lead to this situation are varied. The most important one is the vigorous development of Chinese culture industries. The rapid development of the cultural industries has created a huge increase in the value of the cultural industries, and the economic income created by cultural industries has accounted for more and more of the proportion of GDP in China. The concept of "culture" is becoming more and more popular and in the same time, the trend to make culture "creative" and “industrialization"is gradually enhanced. In the consumption field, consumers' demand for cultural consumption is growing. As the cultural intermediary to cultural industries, simultaneously as one of an important platforms for cultural consumption, the continuous improvement of the status of the cultural NPO is a kind of inevitable trend. ${ }^{[4]}$

However, the proportion of cultural NPO in China NPO is so small from the perspective of totality. Although it is showing a gradual increase in the trend, there is still no more than $10 \%$ until 2012. Thus the development of cultural NPO in China still has a long way to go.

\section{The status quo of cultural non - profit organization in the National Cultural Organization (including for-profit organization and non-profit organization)}

The development of cultural organizations( including cultural for-profit organization and cultural non-profit organization) is fast. The absolute number of it increases significantly. The development speed of cultural service industries is the fastest. In comparison with this, although the number of Chinese cultural non-profit organization is increasing, the growth rate is small. As shown in Table 6, the proportion of cultural NPO in cultural organization in nationwide downs from $5.46 \%$ in 2008 to $5.40 \%$ in 2012.

Table 6: Number of the legal persons about cultural and related industries[UNIT:AMOUNT]

\begin{tabular}{|c|c|c|c|c|c|c|}
\hline Age & $\begin{array}{c}\text { Cultural } \\
\text { Organiz } \\
\text { ation }\end{array}$ & $\begin{array}{c}\text { Cultural } \\
\text { manufacturing } \\
\text { industry }\end{array}$ & $\begin{array}{c}\text { Cultural } \\
\text { wholesale and } \\
\text { retail industry }\end{array}$ & $\begin{array}{c}\text { Cultural } \\
\text { service } \\
\text { industry }\end{array}$ & Quantity & $\begin{array}{c}\text { Proportion } \\
(\%)\end{array}$ \\
\hline 2004 & 317900 & 68900 & 51100 & 197900 & & \multicolumn{2}{c|}{} \\
\hline 2008 & 460800 & 88800 & 55300 & 316600 & 25154 & 5.46 \\
\hline 2012 & 663000 & 133000 & 113400 & 416600 & 35808 & 5.40 \\
\hline
\end{tabular}

Data resource:"Chinese culture and related industries statistical yearbook(2013)”

There are various reasons that lead to the small proportion of cultural NPO in cultural organizations nationwide. The first main reason is that now although cultural industries is in a period of vigorous development in China, its development is not mature because of late start and foundation of instability. The development of cultural industries and the development of the cultural non-profit organization is a process of complement each other. Many countries and regions in the West are well developed in cultural industries because of their developed cultural intermediary organizations. ${ }^{[5]}$ This is one of the major problems in the development of Chinese cultural NPO. The second main reason is that the lack of donation consciousness of citizen. In the funding sources of cultural NPO, more than 
$75 \%$ of the United States are from personal daily donations but in China it is less than 20\%. Most of the donations come from business units in China. ${ }^{[6]}$ It is the general low consciousness of charity that hinder the development of Chinese culture non-profit business.

\section{Conclusions}

In general, China is still in the initial stage of the development of the cultural non-profit organization. There are still so many questions that impede its development, such as imperfect policy system, weak propaganda, low recognition and weak public welfare and donation awareness. Of course, in recent years, with the continuous improvement of relevant departments' attention to the cultural NPO, a series of policies are carried out. For example, the regulation called "The measures for the administration of tax collection about institutions, social group, people-run non-enterprise unit(in Chinese) "(1999) contains the content "in the total income of non-profit organizations, a portion of the income items can enjoy the tax exemption policy”; the Eighteenth National People's Congress of the Communist Party of China proposed to "strengthen the construction of major public cultural projects and improve the public cultural service system". In addition to these, there are also many specialized policies and regulations carried out for the development of social group,people-run non-enterprise unit and foundation, such as "Approach to the foundation(in Chinese)" (1988), "Interim Measures for the examination and administration of the registration of people-run non-enterprise unit of Sport(in Chinese)" (2000), "Regulations on the management of foundations" (2004), "The Interim Measures for the preliminary examination of the qualification of the public welfare donations of the national social group(in Chinese)"(2011). All these policies and regulations provide a strong policy support to the development of China cultural NPO. And at the same time in a certain extent, they also provide the traction and guidance function in the economic level.

In the development of cultural NPO, China can learn from the experience of developing countries or regions that are earlier and more mature in the development of non-profit organization and make a choice according to China's economic, political and cultural reality to realize the development of the cultural non profit organization fast and well.

\section{Acknowledgements}

The research is supported by the National Natural Science Foundation of China (Grant No.71103127); The National Natural Science Foundation of China (Grant No.71473176); Shanghai Philosophy and Social Science Planning Project(Grant No.2014BGL001) .

\section{References}

[1]Shuying Li, Fei Wei.Ethical features and functions of non-profit organizations[J].Philosophy dynamics.2015.06:76-82.

[2]Dan Jin. Social capital and regional economic growth:an empirical analysis based on China's regional perspective[J]. Soft science.2012.09:89-94.

[3]Weilei Chen.The operational mechanism, strategy and logic of government and non-profit organization: a sociological analysis of government purchasing social work service project[J]. Journal of public management. 2014.03:93-105+142-143.

[4]Xiaoyan Jing, Libo Zhao.Research on social forces participating in the construction of public cultural service system[J]. Journal of Fujian provincial Party School of CPC. 2015.05:70-76.

[5]Youyuan Guan, Lianzhi Qiu.Research on the change of the resource recruitment strategy of non-profit organization:take the Taiwan Unite Organization as an example[J].China non-profit making comments.2010.01:188-220. 